\title{
Indicators of marine ecosystem integrity for Canada's Pacific: An expert-based hierarchical approach
}

Thomas A. Okey ${ }^{a, b, *}$

${ }^{a}$ Ocean Integrity Research, 200-825 Broughton Street, Victoria, BC, V8W 1E5, Canada

${ }^{b}$ University of Victoria, School of Environmental Studies, PO Box 1700 STN CSC, Victoria, BC, V8W 2Y2, Canada

* Corresponding author. Tel.: +1 (250) 208-0677.

E-mail address: Thomas.Okey@gmail.com (T.A. Okey).

\section{HIGHLIGHTS}

- A toolkit was developed to guide ecological indicator selection for any context

- A framework of aspects, elements, and features represented ecosystem integrity

- Over 200 experts helped rate indicator selection criteria and rank indicators

- Seventeen expert panels ranked >1000 candidate indicators for 17 ecosystem features

- Ranked lists of indicators with regional relevance guide local indicator selection

\section{GRAPHICAL ABSTRACT}

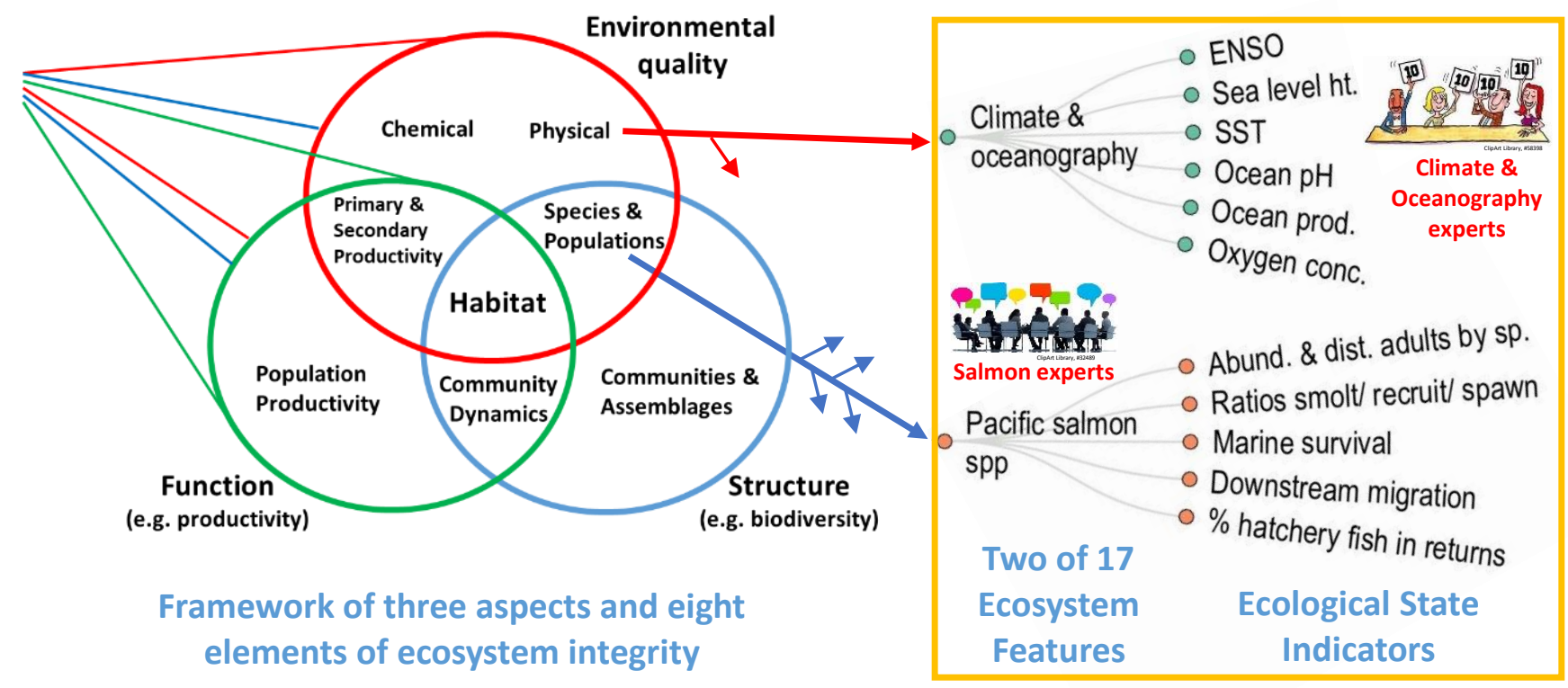




\begin{abstract}
There is great interest and rapid progress around the world in developing sets of indicators of marine ecosystem integrity for assessment and management. However, the complexity of coastal marine ecosystems can challenge such efforts. To address this challenge, an expert-based, hierarchical, and adaptive approach was developed with the objectives of healthy marine ecosystems and community partnerships in monitoring and management. Small sets of the topranked indicators of ecosystem integrity and associated human pressures were derived from expert-rankings of lists of identified candidate indicators of the status of, and pressures on, each of 17 ecosystem features, organized within 8 elements in turn within 3 overlapping aspects of ecosystem health. Over 200 experts played a role in rating the relative value of 1,035 candidate indicators. A panel of topic experts was assigned to each of the 17 ecosystem features to apply 21 weighted indicator selection criteria. Selection criteria and candidate indicators were identified through literature reviews, expert panels, and surveys, and they were evaluated in terms of the experts' judgements of importance to the health of Canada's Pacific marine ecosystems. This produced a flexible, robust, and adaptable approach to identifying representative sets of indicators for any scale and for any management unit within Canada's Pacific. At the broadest scale, it produced a top 20 list of ecosystem state and pressure indicators. These top indicators, or other sets selected for smaller regions, can then guide the development of both regional and nested local monitoring programs in a way that maximizes continuity while including locally unique values. This hierarchical expert-based approach was designed to address challenges of complexity and scale and to enable efficient selection of useful and representative sets of indicators of ecosystem integrity while also enabling the participation of broad government and stakeholder communities.
\end{abstract}

Keywords: Ecological indicators, integrated assessment, expert knowledge, monitoring, ecosystem-based, community-based

\title{
1 Introduction
}

Ecological indicators can provide representative metrics of ecosystem health and pressures, thereby providing simplified foundations for assessment and management (e.g. Costanza et al., 1992; Levin et al., 2008; Levin et al., 2009). Although the field developed rapidly (Niemi and McDonald, 2004), identifying such indicators can be challenging (Dale and Beyeler, 2001), especially for marine ecosystems, which are complex, difficult to study, and full of surprises (Doak et al., 2008) and especially for coupled human and natural systems, which bring additional levels of complexity and uncertainty (Liu et al., 2007). 
A representative set of indicators can be comprised of any of the broad spectrum of classes of ecological indicators, ranging from simple indicators such as those related to individual species and contaminants to aggregate/composite and holistic/integrative indicators. Approaches to aggregation and integration of ecological indicators has advanced considerably during the last decade (e.g. Borja et al., 2009a; Borja et al., 2014; Borja et al., 2009b; Burgass et al., 2017; Gan et al., 2017; Jørgensen et al., 2010; Langhans et al., 2014; Link and Browman, 2014; Probst and Lynam, 2016) as practitioners seek simple ways of assessing complex ecosystems and the pressures on them. The types of indicators utilized in each situation depend on the identified objectives and the availability of information and approaches for monitoring or analysis.

There is great interest, for example, in indicators of the effect of fishing on marine ecosystems (Branch et al., 2010; Coll et al., 2010; Cury and Christensen, 2005; Fulton et al., 2005; Methratta and Link, 2006). The IndiSeas program is designed to evaluate the effects of fishing on the health status of currently 30 marine ecosystems on four continents, including the West Coast of Vancouver Island, Canada. That program's objective of understanding fishingrelated system status and values led to the development of fisheries-related indicators of ecological health / biodiversity and the human dimension (Coll et al., 2016; Shin et al., 2012).

Although fishing is well known as one of the principal drivers of degradation of marine ecosystems (e.g. Myers and Worm, 2003; Pauly et al., 1998), it is but one of many pressures. Recent efforts, particularly in Europe, to develop and catalogue marine biodiversity indicators (Heiskanen et al., 2016; Hummel et al., 2015; Teixeira et al., 2016) have done so with reference to a broad range of pressures.

The complexity of pressures adds to the inherent complexity of marine ecosystems, underscoring the need for integration. The Ocean Health Index (OHI) (Halpern et al., 2012) is a well known global index that compares and tracks 221 countries using "ten diverse public goals for a healthy coupled human-ocean system." It is being applied to Canadian settings (Daigle et al., 2017) with an emphasis on understanding the relative public priorities of ten goals that relate to the benefits marine ecosystems provide to humans. The $\mathrm{OHI}$ is thus more of an index of human benefit than of ecosystem integrity or health per se (eg. Anonymous, 2012; Uusitalo et al., 2016), and it is limited by scale issues and resolution of information (eg. Frazier et al., 2016). These limitations conspicuously underscore the overall challenge of simplifying complexity. Alternative integrative approaches are highlighted in a recent review by Borja et al. (2016).

Integrated indicators can also be derived from ecosystem modelling (Bourdaud et al., 2016; Masi et al., 2017; Shannon et al., 2014) and other analyses such as vulnerability assessments that are habitat-based (e.g. Okey et al 2015) given that habitat is the nexus element that integrates all aspects of ecosystem health. See discussions of integrated versus simple indicators in de Jonge et al. (2012), Okey et al. (2015), Borja et al. (2009b), Borja et al. (2014) and Gan et al. (2017).

A considerable amount of information is available about Canada's Pacific marine ecosystems and social-ecological systems. For example, Fisheries and Ocean Canada's Ecosystem Overview and Assessment Reports (EOARs) (e.g. Lucas et al., 2007) and Socioeconomic and Cultural Overview and Assessment Reports (SECOARs)(RCA, 2012) provide 
syntheses of information bordering on the comprehensive, at least for the Pacific North Coast Integrated Management Area (PNCIMA)—one of Canada's five Large Ocean Management Areas (LOMAs). The PNCIMA corresponds to Pacific Canada's Northern Shelf Area (DFO, 2009) and the regional study area of the Marine Planning Partnership for the North Pacific Coast (MaPP ${ }^{1}$ ) (MPPI, 2016; Okey et al., 2014).

A report series from Fisheries and Oceans Canada (eg. Chandler et al., 2017; DFO, 2000) describes the changing status of various indicators of the physical, biological, and fishery resources of Pacific Canada's marine ecosystems during the past 18 consecutive years. Indicator assessment was also the foundation of the Canadian Marine Ecosystem Status and Trends Report (DFO, 2010), including the component reports for the Pacific region (Cummins and Haigh, 2010; Ianson and Flostrand, 2010; Johannessen and McCarter, 2010). A summary of the state of Canada's Oceans is also available (DFO, 2012). Most of the indicators in these valuable reports were historically chosen to assess commercially-important fisheries resources rather than selected a priori to deliberately characterize ecosystem integrity or health more broadly.

Companion studies to the present investigation (Ainsworth et al., 2011; Ban et al., 2016; Cheung et al., 2015; Okey et al., 2015; Okey et al., 2014) focused on the effects of climate change on the region's marine biological communities and fisheries. Although climate change effects is a different question than ecosystem integrity, these efforts provided lists of state and pressure indicators, but the excessive length of such lists can limit their usefulness without approaches to prioritize them (e.g. Tables 1-3 in Okey et al., 2014). This was similarly encountered by an Australian marine climate impacts initiative that the present author helped design and conduct (Hobday et al., 2006; Poloczanska et al., 2007). One way the challenge of an unwieldy set of indicators was addressed in the Australian case was through synthesis into a regular report card (Poloczanska et al., 2012), which also facilitated public communication of the changing state of the system (see also Doren et al., 2009; Harwell et al., 1999; Loomis and Paterson, 2014; Zador et al., 2017).

As part of the Strait of Georgia research initiative (Masson and Perry, 2013) in the southern part of Canada's Pacific region (Fig. 1), Perry and Masson (2013) addressed this challenge by deriving a reduced set of six driver / pressure indicators by statistically revealing the smallest set of indicators that accounted for the largest proportion of ecological variability.

\footnotetext{
${ }^{1} \mathrm{MaPP}$ is a partnership between the Province of British Columbia and twenty member First Nations (as represented by the Coastal First Nations - Great Bear Initiative, the North Coast-Skeena First Nations Stewardship Society, and the Nanwakolas Council) to plan for the sustainability of coastal and marine areas in four sub-regions of Canada's Pacific marine ecosystems: Haida Gwaii, North Coast, Central Coast, and North Vancouver Island.
} 


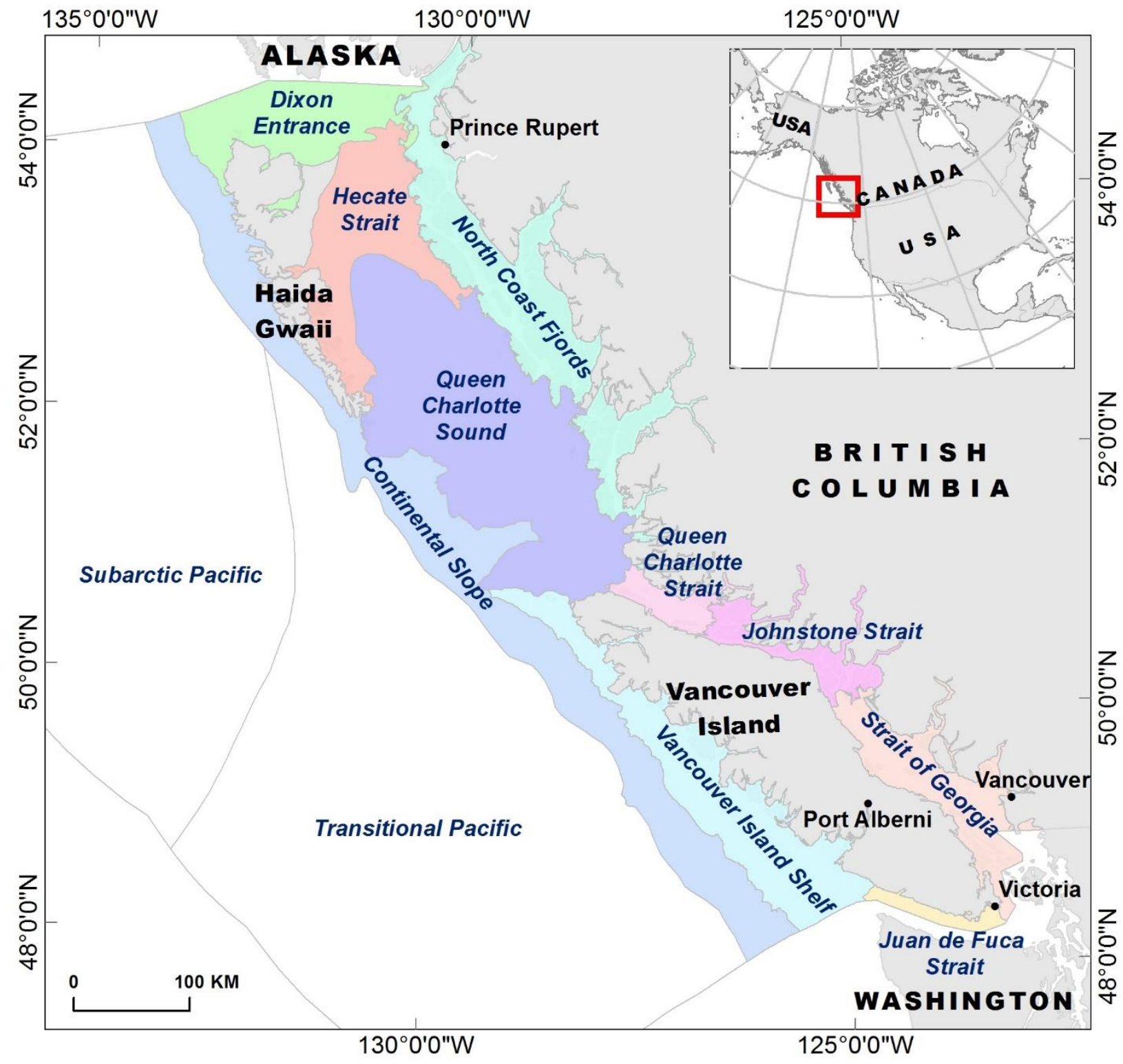

Fig. 1. Canada's Pacific coastal marine ecosystems as delineated by Ecosections, developed through the British Columbia Marine Ecological Classification (BCMEC), British Columbia Land Use Coordination Office (MSRM, 2002). (Map reproduced by Selina Agbayani, WWF Canada).

In the Puget Sound - a large estuary just to the south of Canada's Pacific marine ecosystems - the Puget Sound Partnership conducted an initiative to select portfolios of ecosystem health indicators (James et al., 2012; Kershner et al., 2011; O'Neill et al., 2008). The framework described presently was developed before and during the Puget Sound work, but methodologies differed. While both utilized literature reviews and expert knowledge to identify candidate indicators, the present approach used a purely expert-based approach for indicator evaluation, utilizing the knowledge of 200+ experts. In contrast, a more literature-based evaluation of candidate indicator performance, utilizing about 10 experts, was used in Puget Sound. The convergence of lists of criteria for the selection of ecological indicators was another 
similarity, but those used in the present approach were derived from the literature reviewed as part of this work. After the Puget Sound work, marine ecosystem indicators were developed for Washington State's marine spatial planning process (Andrews et al., 2013). Other valid approaches to select indicators have more recently been developed in Europe (Queirós et al., 2016; Rossberg et al., 2017).

Transboundary indicators (TBI) of marine ecosystem health have been developed for the Salish Sea ecosystem (Wong and Rylko, 2014) under a Joint Statement of Cooperation (SoC) between Environment and Climate Change Canada (ECCC) and the US Environmental Protection Agency (EPA), and that work is ongoing. The Salish Sea is a transboundary sea that includes Canada's Georgia Basin, the USA's Puget Sound, and the shared Juan de Fuca Strait between the Olympic Peninsula and Vancouver Island.

The objectives of the present exercise were to develop a set of indicators of ecological integrity or health of the coastal marine ecosystems of Canada's Pacific (Fig. 1) with relevance to all aspects and elements of ecosystem health, and relevant to all stressors / pressures. The objectives were also to develop indicators that would facilitate monitoring and management of natural resources by coastal communities and other partners in Canada's Pacific including by First Nations and provincial and federal entities while optimizing the potential for high resolution and scale-appropriate ecological information. The present approach is thus designed to provide optimal sets of indicators for community-based monitoring and surveillance (Berkes et al., 2007; Raygorodetsky and Chetkiewicz, 2017; Wilson et al., 2018).

Engagement of coastal communities, marine use sectors, and other partners was a main objective in the present initiative, so the focus was more on simple indicators around which monitoring could be developed but which could also be used in future analytical approaches that might include more holistic or integrative indicators (eg. de Jonge et al., 2012). The goal was also to provide an approach to indicator development that would produce a resolution of information on the scale of ecological features and management units of interest at any scale within Canada's Pacific marine region, such as the MaPP sub-regions (MPPI, 2016).

Ecosystem integrity is defined here more specifically than by Foley et al. (2010) as both the degree of pristine quality of a physical/chemical environment and the degree of pristine structure and functions of associated biological communities - resilience being but one function of biological communities. Ecosystem health is used here as a more accessible, albeit a more subjective, metaphor of integrity. Both terms imply an increasingly elusive notion of equilibrium in a regional ecosystem that is in reality shifting ever-more rapidly with global environmental change (Cheung et al., 2015; Okey et al., 2014). Others have similar perspectives on ecosystem integrity and health (Borja et al., 2013; Borja et al., 2010; Tett et al., 2013). Due to the emerging non-stationarity of ecosystems, function could be emphasized as the most practically meaningful aspect of ecosystem integrity or "health," but 'function' was not given more weight here than 'structure' and 'environmental quality'.

Given the need for an efficient and frugal approach to the development of ecological indicators, an expert-based approach was designed that produced ranked lists of ecological 
indicators for 17 ecosystem features derived for Canada's Pacific marine ecosystems. These 17 ecosystem features were developed as regionally-relevant articulations of 8 elements within 3 overarching aspects of ecosystem integrity/health modified from Eastern Scotian Shelf Integrated Management Strategy (ESSIM) framework (DFO, 2007). These 8 elements and 17 ecosystem features were based on general objectives and key ecosystem attributes identified in key contributions that emerged from the broad literature review undertaken here (e.g. Belfiore et al., 2006; DFO, 2007; Levin et al., 2011). They were also based on marine planning processes in Pacific Canada such as along the West Coast of Vancouver Island (Okey and Loucks, 2011; WCA, 2012) with attention to the Pacific North Coast Integrated Management Area (PNCIMA) through the Marine Planning Partnership of the North Coast (MaPP). Panels of experts were identified and convened for each of these 17 features to evaluate long lists of candidate indicators relevant to each ecosystem feature by applying weighted lists of ecological indicator selection criteria that 81 of the $>200$ experts rated for perceived importance in $\mathrm{BC}$ marine ecosystems.

Although based on and consistent with existing frameworks, the present approach is novel in its extensive systematic expert-based and hierarchical approach, though Loomis and Paterson (2014) developed human dimension indicators using a hierarchical approach. The approach employed herein produced a highly flexible and adaptable tool to efficiently select indicators that are pre-ranked for this region, resulting in useful sets of ecological indicators across scales of investigation.

The framework developed here for selecting sets of ecological indicators is consistent with calls for rigour in such processes (e.g. Niemeijer and de Groot, 2008), and it is notably consistent with the framework of Rice and Rochet (2005) and Rochet and Rice (2005) for the development of indicators for ecosystem-based fisheries management. The indicators were ranked based on expert knowledge and expert perception of the relative importance of selection criteria rather than on their evaluated performance.

The focus was on developing state and pressure indicators with reference to the DriverPressure-State-Impact-Response (DPSIR) framework, which describes the flow and feedbacks of cause and effect (Borja et al., 2006; Elliott, 2002; Jennings, 2005; Levin et al., 2008). Some state indicators of environmental quality also emerged as environmental drivers of the state of biological components, sometimes blurring the line between state and pressure indicators. Such environmental drivers are distinct from social drivers in the DPSIR framework. Some of the early development of this approach was documented in a Social-Ecological Assessment (SEA) of the West Coast of Vancouver Island (WCVI) (Okey and Loucks 2011), which was modelled after Integrated Ecosystem Assessment (Levin et al., 2008; Levin et al., 2011; Levin et al., 2009; Tallis et al., 2010), and was thus intended for use in management and solution-making in addition to assessment of states, pressures, and changes.

The present contribution describes a basic approach to developing a set of ecological indicators for Canada's Pacific marine ecosystems, which can be considered a toolbox or general guidance or advice for selecting sets of ecological indicators for specific circumstances. The 
ranked lists presented herein allow any number of indicators to be selected for many given purposes in Canada's Pacific marine ecosystems. This logical and regional expert-based approach provides for optimal continuity of indicators across a whole region, but individual communities or projects can and should still select even more locally meaningful indicators using the indicators from the present framework as a guide that can provide regional continuity and relevance.

\section{Methods}

The conceptual framework used in the present exercise was based on recognition of three aspects of ecosystem integrity, eight elements within those aspects and 17 ecosystem features. Panels of identified topic experts were assembled for each ecological feature from an overall pool of 200+ experts. Twenty-one criteria for the selection of ecological indicators identified through a broad literature review were rated for perceived relative regional importance by the overall expert pool. These weighted criteria were used by each of the 17 expert panels to evaluate and rank lists of candidate indicators from the 1,000+ overall list of indicators identified from broad literature reviews and expert knowledge. This resulted in ranked lists of indicators for each of the 17 ecosystem features. These lists can be used to select useful sets of indicators for any given management unit or area based on the relative presence or importance of each ecosystem feature in the management unit or area. The approach is described in more detail below.

\subsection{Identify a guiding conceptual framework}

The ecosystem framework developed for the Eastern Scotian Shelf Integrated Management Strategy (ESSIM) framework (DFO, 2007) was modified by overlapping the three aspects of ecosystem integrity in a Venn diagram (Fig. 2) highlighting their interconnections. Four of the eight elements support multiple aspects of ecosystem health or integrity. Habitat is a central nexus element of ecosystem integrity or health, supporting all three aspects. 


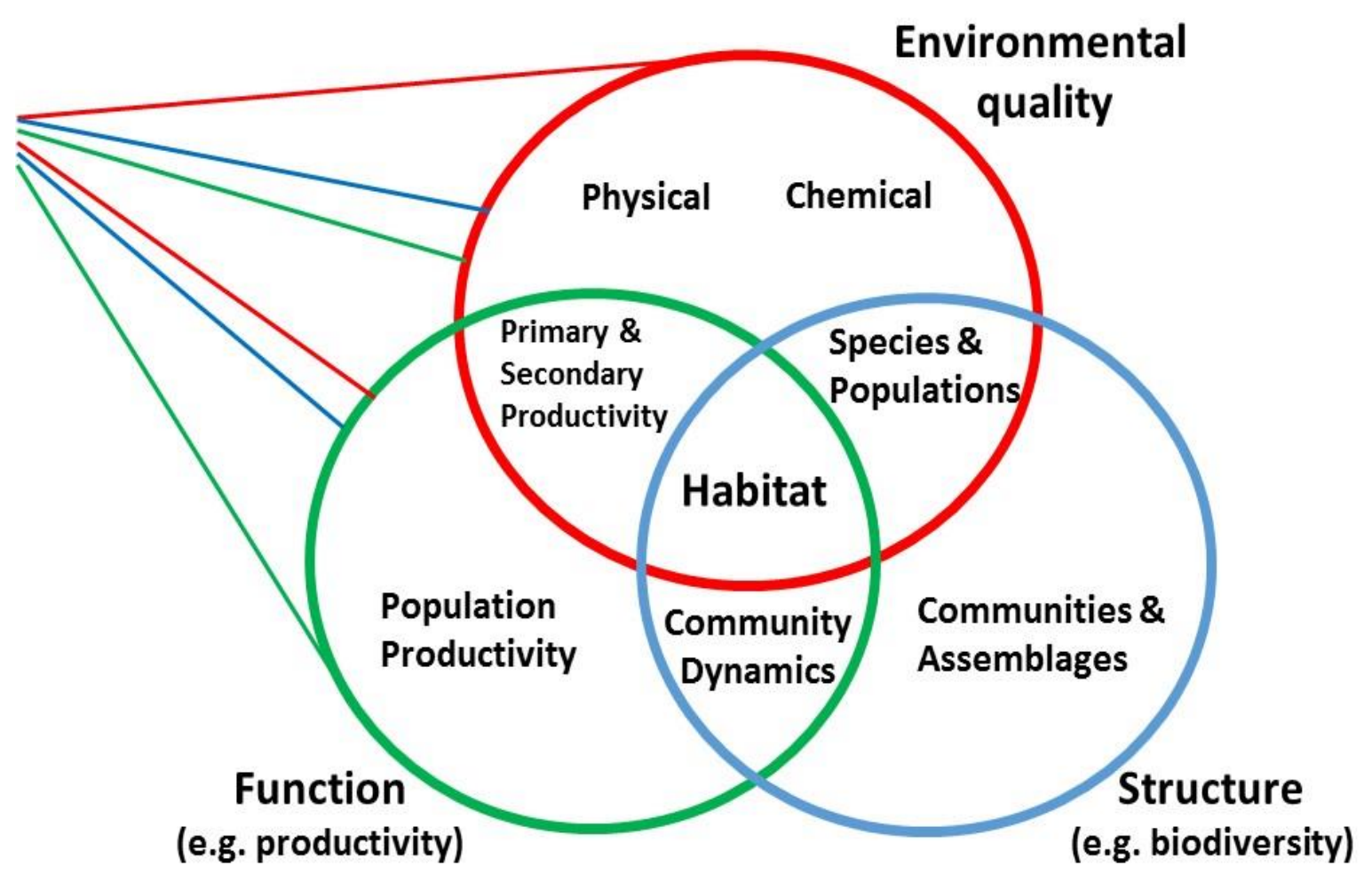

Fig. 2. Eight ecosystem elements arranged in relation to the three general aspects of ecosystem integrity: environmental quality, structure, and function. This was partly inspired by the Eastern Scotian Shelf Integrated Management Strategy (ESSIM) framework (DFO 2007), but in this refined depiction four ecosystem elements are members of two or three aspects of healthy ecosystems. The lines on the left denote that each element and aspect changes through time (modified from Okey et al., 2011).

\subsection{Identify ecological features relevant to each element}

Seventeen ecological features were identified within the eight elements (Table 1). These features were selected to address pertinent goals and objectives (Belfiore et al., 2006; DFO, 2007; Okey and Loucks, 2011) and key ecosystem attributes (Belfiore et al., 2006; Levin et al., 2011), and they were subject-matter themes for the expert panels that rated lists of candidate state and pressure indicators. The hierarchical approach to selecting these 17 features deconstructs and represents the three aspects of healthy ecosystems, and especially cross-cutting elements such as habitat and community dynamics (Fig. 2, Table 1). This framework is consistent with the Intergovernmental Oceanographic Commission Integrated Coastal and Ocean Management (IOC ICOM) framework (Belfiore et al., 2006). 
Table 1. Ecosystem features under eight ecosystem elements, and three aspects of ecosystem health. The nexus element 'habitat' and the other cross-cutting element 'community dynamics' - are added to the matrix, showing how the features broadly represent these elements and aspects. The 17 aggregated features corresponded to 17 expert panels that considered and rated unique lists of candidate indicators using four aggregated dimensions of 21 ecological indicator selection criteria (Table 2).

\begin{tabular}{|c|c|c|c|c|c|c|}
\hline \multirow[b]{2}{*}{ Element } & \multirow[b]{2}{*}{ Feature } & \multicolumn{3}{|c|}{ Aspect } & \multirow[b]{2}{*}{ 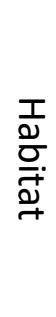 } & \multirow{2}{*}{$\begin{array}{l}0 \\
\frac{0}{3} \\
\frac{3}{3} \\
\frac{0}{3} \\
\frac{0}{3} \\
\frac{0}{3} \\
\frac{1}{n}\end{array}$} \\
\hline & & 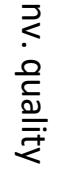 & 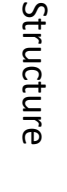 & 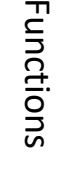 & & \\
\hline \multirow{2}{*}{ Physical } & 1. Climate and oceanography & $Y$ & & & $Y$ & \\
\hline & 2. Marine noise pollution & $\mathrm{Y}$ & & & Y & \\
\hline \multirow{2}{*}{ Chemical } & 3. Water and sediment quality & $\mathrm{Y}$ & & & $\mathrm{Y}$ & \\
\hline & 4. Bioindicators of pollution & $\mathrm{Y}$ & $\mathrm{Y}$ & $\mathrm{Y}$ & $\mathrm{Y}$ & \\
\hline Productivity & 5. Plankton and productivity & & $\mathrm{Y}$ & $\mathrm{Y}$ & & $\mathrm{Y}$ \\
\hline \multirow{6}{*}{$\begin{array}{l}\text { Species / } \\
\text { Populations / } \\
\text { Population } \\
\text { Productivity }\end{array}$} & 6. Seabirds and shorebirds & & $\mathrm{Y}$ & $\mathrm{Y}$ & & $\mathrm{Y}$ \\
\hline & 7. Marine mammals & & $\mathrm{Y}$ & $\mathrm{Y}$ & & $\mathrm{Y}$ \\
\hline & 8. Forage fishes & & Y & Y & & Y \\
\hline & 9. Pacific salmon species & & $\mathrm{Y}$ & $\mathrm{Y}$ & & $\mathrm{Y}$ \\
\hline & 10. Invertebrates & & Y & Y & & Y \\
\hline & 11. Invasive / unusual species / disease & $\mathrm{Y}$ & $\mathrm{Y}$ & $\mathrm{Y}$ & & $\mathrm{Y}$ \\
\hline \multirow{5}{*}{$\begin{array}{l}\text { Communities / } \\
\text { Assemblages }\end{array}$} & 12. Kelp / macroalgae communities & $\mathrm{Y}$ & $\mathrm{Y}$ & $\mathrm{Y}$ & $Y$ & $\mathrm{Y}$ \\
\hline & 13. Seagrass communities & Y & Y & Y & Y & Y \\
\hline & 14. Intertidal communities & $\mathrm{Y}$ & Y & $\mathrm{Y}$ & Y & $\mathrm{Y}$ \\
\hline & 15. Subtidal benthic communities & $\mathrm{Y}$ & Y & $Y$ & $\mathrm{Y}$ & $\mathrm{Y}$ \\
\hline & 16. Fish communities & & Y & $\mathrm{Y}$ & & $\mathrm{Y}$ \\
\hline Habitat & 17. Shoreline integrity and habitat & $\mathrm{Y}$ & $\mathrm{Y}$ & & $\mathrm{Y}$ & \\
\hline $\begin{array}{l}\text { Community } \\
\text { dynamics }\end{array}$ & Integrative and trophic indicators & & $\mathrm{Y}$ & $\mathrm{Y}$ & & $\mathrm{Y}$ \\
\hline
\end{tabular}

\subsection{Identify experts relevant to each ecological feature}

Panels of experts were identified for each ecosystem feature using an expert database from the British Columbia Marine Conservation Analysis (BCMCA), and based on participation in symposia and workshops, and using the present author's expert knowledge, judgment, and networking. Over 200 experts were identified, and their expertise and education were sampled during expert surveys in which they participated. Most participants identified themselves as having expertise in ecology, biology, and marine fields. Most respondents held PhDs, and about a quarter master's degrees as their top education level (Appendix A).

Separate surveys were developed for each expert panel, except for the first survey to the whole group on rating perceived regional importance of ecological indicator selection criteria 
(see Appendix B). Separate feature-based subject-matter surveys enabled each expert to be confronted only with evaluating indicators in their specific field(s) of expertise.

\subsection{Identify and rate criteria for selecting ecological indicators}

Ecological indicator selection criteria were initially adapted from Dale and Beyeler (2001) and Rice and Rochet (2005). This list was checked against the work of the Puget Sound Partnership (PSP) (Levin et al., 2011; O'Neill et al., 2008), which included extensive reviews of indicators and the use of nineteen indicator criteria. Other lists were also considered including the SARD (Sustainable Agriculture and Rural Development) cultural indicators for indigenous peoples' food systems (Woodley et al., 2009), WCA's social-ecological assessment framework (Okey and Loucks, 2011), the Ocean Health Index (Halpern et al., 2012), and Washington State Academy of Sciences Committee review of the Puget Sound Partnership's development of social-ecological indicators (WSASC, 2012).

Several recommendations from these reports were addressed, including separating criteria related to scientific soundness from considerations of relevance or practicality; linking candidate indicators to functional relationships, key attributes or features, and pathways of effects; balancing and identifying indicator types including structural, process, and results-based indicators; and the importance of a selection process guided by theory but grounded in relevance and practicality.

The resulting list of ecological indicator selection criteria (Table 2) was ranked by 81 experts, out of the $200+$ invited, based on their perceptions of relative importance for the region using the first expert survey of this indicator selection series (Survey 1 in Appendix B).

For experts to easily apply these criteria to lists of candidate indicators, they were aggregated under four broader dimensions of selection criteria, and a weighting index for each dimension was derived as proportional to the average weight of all the individual selection criteria in that dimension (Table 2). Each expert panel (associated with each of 17 ecological features) could thus contribute to a reasonably simple exercise of rating each candidate indicator using only four dimensions that integrate 21 ecological indicator selection criteria.

\subsection{Identify candidate indicators within ecological features}

The 1,020 candidate indicators were identified iteratively throughout this initiative beginning with lists for each feature based on a broad literature review and expert judgement (see Okey et al., 2011). These lists were expanded and refined by the experts in each expert panel through two iterations of surveys tailored to each panel (Surveys 2 and 3 in Appendix B). The resulting list of candidate indicators included both state and pressure indicators. 
Table 2. Mean ratings of the perceived relative importance of 21 ecological indicator selection criteria $(n=81)$. Levels of importance included: $0=$ not, $1=$ low, $2=$ medium, $3=$ high, $4=$ very high, $5=$ essential. Bolded values are the grand means of the ratings of the four dimensions of criteria, and in parentheses the relative index of each grand mean, which was used to weight the ratings of each candidate indicator by each expert panel.

\begin{tabular}{lc}
\hline Selection criteria & $\begin{array}{c}\text { Mean rating } \\
\text { (Relative index) }\end{array}$ \\
\hline Scientifically sound & $\mathbf{3 . 2 0}(\mathbf{1 . 0 0})$ \\
Theoretically-sound & 3.67 \\
Sensitivity to stressors & 3.48 \\
Responds predictably \& sensitive to attribute changes & 3.27 \\
High signal-to-noise ratio & 3.22 \\
Linkable to science-defined reference points / targets & 3.14 \\
Responds predictably and in a known way to stressors & 3.09 \\
Continuous time series & 3.06 \\
Reflective of system thresholds or surprise & 3.03 \\
Specificity of response to stressors & 2.81 \\
& \\
\hline Relevant, meaningful, and understandable & $\mathbf{2 . 9 9 ( 0 . 9 4 )}$ \\
Broadly perceived as reliable and meaningful & 3.38 \\
Relevant to management concerns & 3.27 \\
Regionally/nationally/internationally compatible & 2.71 \\
Easy to understand & 2.61 \\
& \\
\hline Practical and efficient to implement & $\mathbf{2 . 9 0}(\mathbf{0 . 9 1})$ \\
Spatial and temporal variation understood & 3.38 \\
Broad spatial coverage & 3.00 \\
Historical data available & 2.93 \\
Numerical & 2.79 \\
Cost efficient & 2.68 \\
Easy to measure & 2.64 \\
& \\
\hline Part of balanced suite of indicators & $\mathbf{2 . 8 6}(\mathbf{0 . 8 9})$ \\
Anticipatory of broader ecosystem changes & 3.26 \\
Complements existing indicators & 2.46 \\
\hline
\end{tabular}

\subsection{Rate and rank candidate indicators for each feature}

In the final survey (Survey 4 in Appendix B), expert participants were asked to rate each of the candidate indicators in their feature of expertise for each of the first three dimensions of ecological indicator selection criteria — scientific soundness, relevance, practicality. The ratings were associated with scores of 1 to $4(1=$ low, $2=$ medium-low, $3=$ medium-high, and $4=$ high $)$ and zero for cannot judge. Each indicator's weighted average score was calculated for each dimension by multiplying the number of responses per rating by the score and dividing by the number of non-zero responses, then adding up the weighted scores. For example, the weighted average for each indicator was calculated as follows: 
Weighted average $=\sum \mathrm{R}_{1} * 1 / \mathrm{N}+\sum \mathrm{R}_{2} * 2 / \mathrm{N}+\sum \mathrm{R}_{3} * 3 / \mathrm{N}+\sum \mathrm{R}_{4} * 4 / \mathrm{N}$

where $\mathrm{R}$ is the number responses per score and $\mathrm{N}$ is the number of non-zero responses for the indicator in total.

This produced an average rating score for each indicator under each dimension of ecological indicator selection criteria (the average score from respondents in the expert panels for each feature). An indicator's average score for each dimension could be summed for an overall score to compare with other indicators. The average scores of the candidate indicators were corrected by applying the weighting indices shown in Table 2 to each dimension of ecological indicator selection criteria, thereby producing overall indicator scores weighted by expert perceptions of the relative importance of each ecological indicator selection criteria or dimension.

\section{Results}

The weighted ranking exercise by each of the 17 expert panels resulted in ranked lists of candidate state and pressure indicators for each feature (Tables C.1 and C.2 in Appendix C). The elements, ecosystem features, and top 5 ranked indicators are displayed in a radial dendrogram (Fig. 3).

An overall list of top 20 state indicators was then developed to minimally represent the integrity of Canada's Pacific marine ecosystems, along with the top 20 associated pressure indicators (Table 3). These were based on the top five ranked state and pressure indicators from the expert-based quantitative ratings of $>1,000$ candidate indicators by the $200+$ subject matter experts in the 17 expert panels associated with the 17 ecological features under the 8 elements and 3 aspects of ecosystem integrity, using the 21 weighted ecological indicator selection criteria binned under 3 dimensions (Tables C. 1 and C. 2 in Appendix C). Some of the state indicators listed in Table 3 combine the top 5 ranked indicators from Table C. 1 or are moved to more appropriate categories to reduce redundancy or are slightly re-expressed for a clearer summary.

Most of the pressure indicators listed in Table 3 are presented as multiple pressures associated with each state indicator, in descending order of ranked importance. This sometimes produced (complementary) composite indicators for both state and pressures, but pressure indicators associated with state indicators were particularly compounded given that the overall pressure on any given ecological feature is a function of the cumulative impact of multiple pressures. A composite of the top pressures best represents the overall pressure on each feature. 


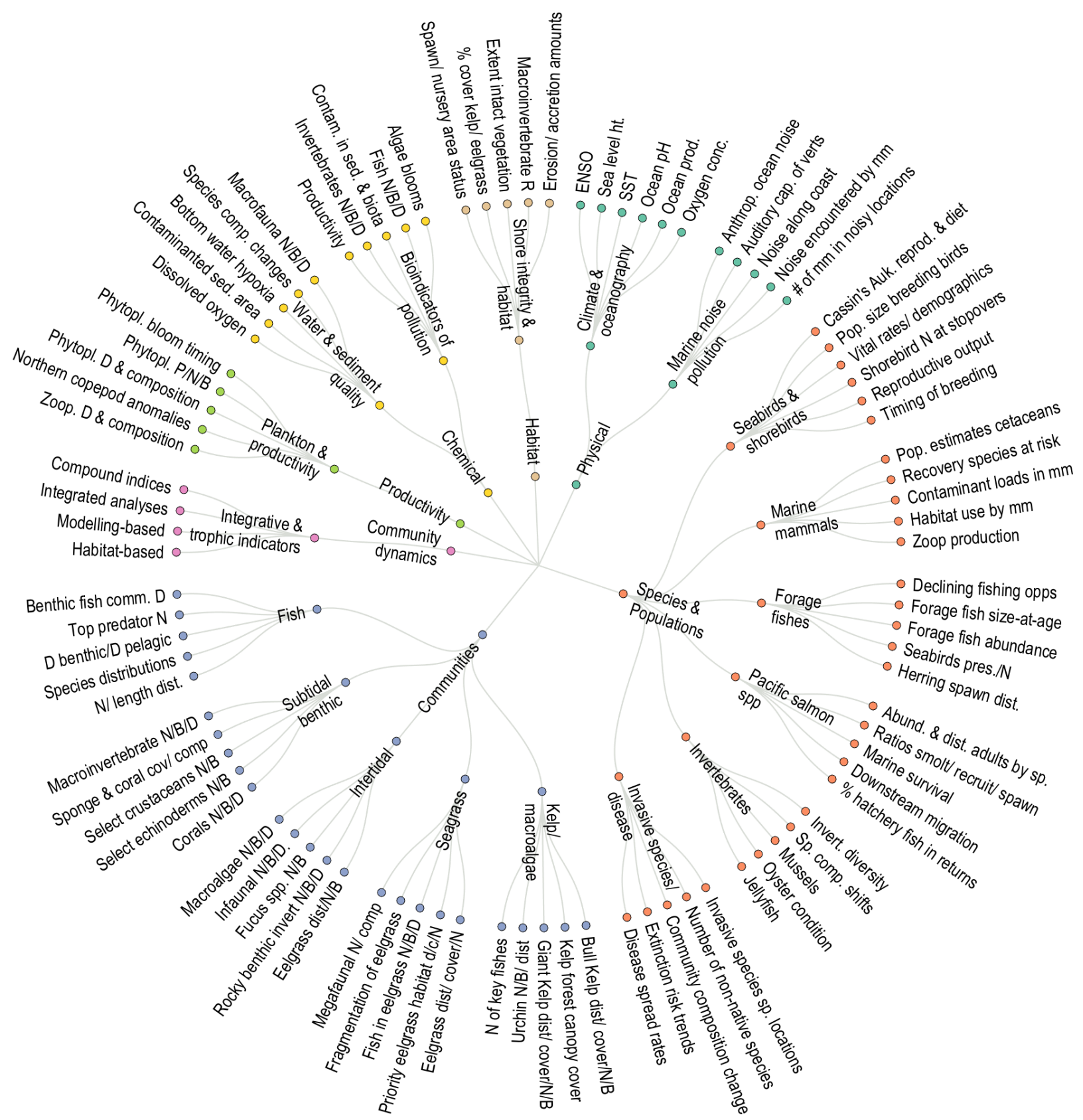

Fig. 3. Radial dendrogram of the elements (center circle), ecosystem features (intermediate circle), and top 5 ranked indicators (outer circle) that participating experts considered to represent the integrity or health of Canada's Pacific Marine Ecosystems. Indicators are simplified and abbreviated from those shown in Table $\mathrm{C} 1$ in Appendix $\mathrm{C}$. Rankings of indicators within each feature are ordered clockwise. $\mathrm{N}$ is number of individuals and $B$ is biomass - both of which could be measured in relation to area or volume. $D$ is species diversity, which is species richness (R) weighted by evenness, but $R$ is preferred for comparative indicators (figure by Kelly Kearney, University of Washington, Joint Institute for the Study of the Atmosphere and Ocean (JISAO)). 
Table 3. Overall top 20 indicators of the integrity of Canada's Pacific marine ecosystems, and the top 20 associated pressure indicators. Many of these indicators are listed as composite indicators, especially the pressure indicators. Bolded pressure indicators also serve as state indicators for other ecological features.

\begin{tabular}{|c|c|c|c|}
\hline Element & Ecological features & State indicators & Pressure indicators \\
\hline Physical & $\begin{array}{l}\text { Climate and oceanography }< \\
\text { Marine noise pollution }\end{array}$ & $\begin{array}{l}\text { Atmos-Ocean indices (ENSO, PDO, ALPI, NPGO, } \mathrm{CO}_{2} \text { ) } \\
\text { Sea level, temperature, } \mathrm{CO}_{2} / \mathrm{O}_{2} \text { conc., salinity, mixing } \\
\text { Anthropogenic ocean noise at specific locations }\end{array}$ & $\begin{array}{l}\text { Emissions of greenhouse gasses } \\
\text { Watershed modification } \\
\text { Seismic surveys and ship activity }\end{array}$ \\
\hline Chemical & $\begin{array}{l}\text { Water \& sediment quality } \\
\text { Bioindicators of pollution }<\end{array}$ & $\begin{array}{l}\text { Contaminants / pH / nutrients / turbidity } \\
\text { Contaminant loads in fauna; areal extents affected } \\
\text { Infaunal compositions and indicator species }\end{array}$ & $\begin{array}{l}\text { Outfalls, non-point runoff, watersheds, ships, physical } \\
\text { Outfalls, non-point runoff, watersheds, ships, physical } \\
\text { Water and sediment quality }\end{array}$ \\
\hline Productivity & Plankton \& productivity & Chl. $a$ and zooplankton species compositions & Water quality, climate / oceanography \\
\hline $\begin{array}{l}\text { Species / } \\
\text { Populations / } \\
\text { Population } \\
\text { productivity }\end{array}$ & $\begin{array}{l}\text { Seabirds and shorebirds } \\
\text { Marine mammals } \\
\text { Forage fish } \\
\text { Pacific salmon } \\
\text { Invertebrates } \\
\text { Invasive/unusual spp./disease }\end{array}$ & $\begin{array}{l}\text { Abundance of breeding seabirds (e.g. Cassin's Auklet) } \\
\text { Abundance of cetaceans, pinnipeds, otters } \\
\text { Species abundance / condition / composition } \\
\text { Abundance / distribution / condition of adults \& juv. } \\
\text { Invertebrate species composition / condition } \\
\text { Invasive aquatic species extent / distribution }\end{array}$ & $\begin{array}{l}\text { Water qual., plank., forage fish, aliens, bycatch, habitat } \\
\text { Noise, ship activity, fisheries competition/bycatch } \\
\text { Water quality, oceanography, fishing, seabirds } \\
\text { Temp., plankton, fishing rates, watersheds, predators } \\
\text { Temperature, fishing effects, ocean chemistry } \\
\text { Ballast water, boat density, exotic debris, aquaculture }\end{array}$ \\
\hline $\begin{array}{l}\text { Communities } \\
\text { / assemblages }\end{array}$ & $\begin{array}{l}\text { Kelp / macroalgae comm. } \\
\text { Seagrass communities } \\
\text { Intertidal communities } \\
\text { Subtidal benthic comm. } \\
\text { Fish communities }\end{array}$ & $\begin{array}{l}\text { Canopy kelp cover / density / distributions, otter, fish } \\
\text { Eelgrass distribution / cover / density / biomass, fish } \\
\text { Algae/plant/invertebrate compositions } \\
\text { Selected corals and other invertebrates } \\
\text { Species compositions, TL-body size relations, plankt. }\end{array}$ & $\begin{array}{l}\text { Water quality, oceanography, storms } \\
\text { Water quality, anchoring, armoring/develop. } \\
\text { Water and sediment quality } \\
\text { Trawling / fishing, proximity to pollution sources } \\
\text { Comm. and rec. catch \& effort, temperature, plankton }\end{array}$ \\
\hline Habitat & Shoreline integrity and habitat & $\begin{array}{l}\text { Spawning \& nursery areas, shallow kelp \& eelgrass, } \\
\text { marsh areas, riparian vegetation, invert. richness }\end{array}$ & $\begin{array}{l}\text { Invasive macroinverts, armoring/structures, watershed } \\
\text { flow, channel obstruct., aquaculture, sea level }\end{array}$ \\
\hline $\begin{array}{l}\text { Community } \\
\text { dynamics }\end{array}$ & Biological communities & $\begin{array}{l}\text { Integrative and holistic (e.g. trophic) indicators: e.g. } \\
\text { mean trophic level, community longevity index }\end{array}$ & All anthropogenic stressors \\
\hline
\end{tabular}


The state and pressure indicators were then supplemented with the responses of a specific survey question (Appendix B, Survey 4, Question 4) that asked respondents to identify indicators that may have been rated low in the strictly quantitative analysis, but that could be a very important indicator of overall ecosystem integrity or health.

The resulting dynamic set of indicators should be optimal for the design and implementation of assessment and monitoring programs, whether these are designed to evaluate all of Canada's Pacific marine ecosystems or only particular scales of interest. Intensive studies of ecological features should examine rankings of all the candidate indicators for each feature including more than just the top 5 ranked indicators (see Appendix C). Although the ecological indicator selection criteria include sensitivity and anticipation of ecosystem changes (Table 2), and although the overall state and pressure indicators listed in Table 3 can be used to detect change as well as state and pressures, the members of each expert panel were further asked to identify state indicators that stood out as useful for detecting ecosystem change (Appendix B, Survey 3, Question 3). These change indicators are shown in Table D.1 in Appendix D.

The hierarchical expert-based framework of aspects, elements, and features not only produced a reasonably small set of top rated indicators of the overall integrity of Canada's Pacific marine ecosystems (Table 3), but it also produced extensive lists of rated indicators for each ecosystem feature (Tables C.1 and C.2 in Appendix C) enabling deeper examinations of ecological features when desired by particular research groups, or for particular applications.

\section{Discussion}

This hierarchical and representative expert-based approach to identifying and developing ecological indicators for Canada's Pacific was designed as a general framework and toolbox for ease of application at any scale or setting of interest in this region. The approach is portable to other regions around the world if practitioners conduct regionally-unique scoping of ecosystem features and employ expert processes to evaluate candidate indicators of each feature. In tropical settings, for instance, some but not all features would differ from those in British Columbia.

A hierarchical and adaptive framework was intentionally chosen for the expert-based selection of indicators for Canada's Pacific marine ecosystems (Fig. 2, Table 1) because of the inherent complexity in marine ecosystems, and because the integrity, or health, of any given part of complex ecosystems is best represented by a scale-flexible approach. The utility of hierarchical and adaptive frameworks may be universal because many ecological indicators are habitat-specific and scale-dependent such that at least some portion of a small number of simple indicators would not be relevant in all settings in a region, while other indicators might have trans-habitat and trans-scale attributes making them relevant in all settings. This is perhaps truer of indicators of pressures or stress than those of state. This scale-dependency exists partly because there is always some degree of nested ecological or social-ecological complexity throughout the world's coastal marine settings. Furthermore, the multi-jurisdictional nature of ecosystem-based management combined with limited funding for monitoring increases the 
overall complexity of the managed system and otherwise contributes to the challenge of establishing useful sets of indicators.

The expert-ranked lists of state and pressure indicators for each of the 17 ecological features representing 8 elements and 3 aspects of ecosystem integrity is the core of this flexible and adaptive toolbox for the identification of small sets of indicators representing ecosystem health at any preferred scale. For example, if the scale of interest is the entire coastal marine ecosystem of Canada's Pacific, then the top ranked state or pressure indicator for each feature in Tables C.1 and C.2 could be selected using the first three dimensions of the selection criteria as shown in Table 2, producing an overall short-list of integrity indicators for Canada's Pacific marine ecosystems as summarized in Table 3. On the other end of the spectrum, if the scale of interest of a given project comprises only a single feature, such as seagrass communities or kelp forest communities, then larger numbers of state and pressure indicators could be selected from the ranked list of that feature only (Tables C.1 and C.2 in Appendix C).

In the case of some intermediate level of ecological focus or scale, an appropriate set of indicators can be chosen by considering the relative applicability of the 17 ecosystem features to that management unit or ecological setting. The coastal marine region of Canada's Pacific is highly complex, irregular, and heterogeneous (Okey et al., 2015; Okey et al., 2014) such that any given management unit of reasonable size contains multiple habitat types at sometimes high levels of spatial heterogeneity. For instance, this is true of many areas or regions surrounding First Nations or other communities where there is interest in assessment, monitoring, or restoration initiatives. The 17 ecosystem features structuring the present guidance are a mixture of biological communities, populations, and physical and chemical elements of environmental quality, and they include both habitat and "trans-habitat" features; many habitat features occur only in certain regions while trans-habitat features, such as aspects of water quality, occur across all regions. Indicators can be selected from the present toolbox based on the relative presence or relative valued importance of the various features within the management unit. It is this complex mixture of features, integrated in this selection approach, that enables the representation of overall ecosystem health.

The relevance-based selection of features can thus be considered part of the fourth dimension of ecological indicator selection criteria - part of a balanced suite of indicators - to ensure completeness, complementarity, and representativeness. The overall approach should thus result in small set of indicators representing the integrity or health of the marine ecosystem at any given scale or context. It should provide as many of the top rated state and pressure indicators as needed for monitoring or for more rigorous analyses including pathways of effects analyses (Adams, 2005).

To operationalize the selected indicators for monitoring, surveillance, and management, they need to be expressed as measurable metrics and they must be evaluated in relation to target and limit reference points (eg. Borja et al., 2012; Rossberg et al., 2017; Samhouri et al., 2012; Samhouri et al., 2011), which also need development in the context of monitoring designs that account for the spatial and temporal variability of each of those indicators. This requires the 
development of sampling designs for each metric. The selected set of indicators would then theoretically represent the overall ecosystem health of Canada's Pacific, or some other selected scale of interest, assuming that the aspects, elements, and features of the system are sensibly identified and assigned to the unit of interest, and assuming that the specific metrics, reference points, and specific sampling (monitoring), are all rigorously designed and connected to reliable institutional and human capacities.

These are crucial steps after the selection of ecological indicators, and this may best be accomplished through consultation with experts on ecological features, such as the panels of experts. However, practical limits in the use of the expert survey approach was encountered related to respondent fatigue, and so a more personalized and resourced working group approach may be needed for these tasks. Regardless of how this process manifests, dedicated and supported coordination of such continuing steps will be essential for accomplishing this next significant exercise if overall indicators and monitoring initiatives are to have credibility.

Expert judgement is a foundation of multiple steps in the methodology of the present approach to the development of ecological indicators. There is an ongoing discussion in the literature about the value and limitations of the use of expert judgement for ecological indicators and assessment. Hyman and Leibowitz (2001) developed a judgment-based indicator selection approach to ensure "a rigorous and consistent set of indicators even when knowledge about the ability of indicators to represent an endpoint is limited to expert judgement." Similarly, Oppenheimer et al. (2016) advocated formalization of the role of expert judgement in numerical models used for climate change projections. Crochemore et al. (2015) found that expert judgement can be both better and worse than numerical criteria and models. Blanfune et al. (2017) endeavored to minimize the reliance on expert judgement in the CARLIT method for assessment of ecological quality in Mediterranean waters. The purpose of prominent reliance on expert judgement in the present contribution was to ensure the efficient selection broad and representative sets of indicators.

Truly functional partnerships amongst communities, public agencies, and academia are the best hope for the implementation of the monitoring, assessment, and management programs that emerge for Canada's Pacific marine ecosystems and social-ecological systems. Because the present exercise was focused on identifying simple indicator types rather than aggregate or composite indicators (as also reflected in the selection criteria), resulting sets of indicators should enable the participation of coastal communities and other partners from throughout the region. Success in enabling partnerships and integration with coastal communities and across jurisdictions cannot be evaluated until monitoring programs are being designed and implemented in earnest. However, the aspect of the toolbox approach that allows potential partners to pick and choose from expert-ranked lists based on their interests, knowledge, values, and resources empowers partners to be strongly engaged participants and shapers of assessment and management programs.

Existing or ongoing monitoring of marine ecological resources in Canada's Pacific is still highly sporadic and patchy throughout much of the region, as indicated by a previous review of 
existing monitoring (W. Szaniszlo, Pers. Comm., 6 January 2015); see also summary in LGC (2014). Exceptions include monitoring of fisheries resources and oceanography (Chandler et al., 2017; DFO, 2010), intensive monitoring at instrumented ocean observatory stations (Heesemann et al., 2014), monitoring of special conservation areas (e.g. Marliave and Challenger, 2009; Suffling and Scott, 2002), monitoring by private research institutes (e.g. Hunt et al., 2017), and notable and growing efforts of First Nations such as the Coastal Guardian Watchmen Network (Klain et al., 2014; Turner and Bitonti, 2011). Additional data sets for Canada's Pacific are identified by Cisneros-Montemayor et al. (2017) in their metadatabase on the status of Canadian ocean ecosystems.

While fish communities are one of 17 ecosystem features in the present framework of ecosystem integrity, indicators of fisheries per se are not emphasized in the sets of indicators resulting from the present work. The intentional strategy here was to represent ecosystem integrity or health rather than assessing commercially-important resources or strongly emphasizing the importance of existing long-term fisheries datasets, but such indicators can and should complement the derived set of ecological indicators, as should other human dimension indicators of well-being (eg. Daigle et al., 2017; Pinto et al., 2014).

Practical options for progress toward monitoring initiatives are currently still being scoped by communities within the MaPP sub-regions in Canada's Pacific (MPPI, 2016), including prioritizing and using currently monitored indicators during the short term, and selection of indicators through a process of regional indicator selection while developing the capacity to implement and monitor such indicators and metrics. Some consultancies (e.g. LGC, 2014) have done their best to operationalize a sub-optimal set of indicators that have emerged from the MaPP process thus far. The present contribution can help un-confound this regional indicator selection process. Using the present tool-box, communities and practitioners can more easily optimize their indicators, monitoring, and management programs in the sense of maximizing both regional continuity and local relevance of indicators.

Once indicators (and targets) are identified for a given setting, the next general challenge is the development of integrated monitoring programs. A consistent challenge of regional monitoring initiatives involving multiple jurisdictions and stakeholders is the complexity and inconsistency of data collection and data management approaches and platforms. Regional monitoring systems thus require some overarching system such as an online and app-based networking platform for maximizing consistency of monitoring methods, data collection, and communication protocols, as well as to facilitate functional collaborations and partnerships as appropriate.

The Local Environmental Observer (LEO) Network (leonetwork.org) (Brubaker et al., 2013) is one example of a platform and network with capabilities that can meet these challenges. Developed initially with Native Tribal Alaskan communities, this network is being established in British Columbia through the First Nations Health Authority and with initial support of the Commission for Environmental Cooperation, and endorsement of Indigenous and Northern Affairs Canada and Environment and Climate Change Canada. The LEO Network mobilizes and 
connects local observers of unusual environmental changes using an online and app-based platform. It brings together multiple dimensions of knowledge for integration and synthesis (e.g. Hupp et al., 2015; Walsh et al., 2017), including holders of indigenous and Western scientific knowledge. LEO observations include rich visual and audio media in addition to descriptive narrative, and they are published on the LEO database platform as citable stories. It also has quantitative data entry capacities. Contributed and integrated knowledge is shared to, and through, the LEO Network with authorship attribution and free and informed consent of contributors (Boutilier, 2017).

In the future, some of the indicators identified using the approach described herein may be used in projecting or forecasting ecological and social-ecological change as well as the effects of alternative management strategies on the status of these indicators, possibly using formal or informal Management Strategy Evaluation (MSE) (Bunnefeld et al., 2011; Fulton et al., 2014; Smith et al., 1999) and adaptive management (sensu Walters, 1986). Such indicators will thus be integral to the development of effective strategies to manage individual resources and broader social-ecological systems in Canada's Pacific.

The simple goal of resource management and conservation in the context of indicators is to maintain a minimum target level of a given resource by not exceeding limit reference points of one or more representative indicators or metrics. One aspect of Integrated Ecosystem Assessment (IEA)(Levin et al., 2009; Tallis et al., 2010) is a risk analysis in which the risk that an indicator will exceed a limit reference point given a particular management strategy is evaluated either empirically (through monitoring) or through simulation, or both. This provides a practical framework for adaptive management, whereby improvements can be made based on the different outcomes to the indicator's status — as measured by the indicator metric in relation to these reference points.

One way to achieve ecosystem-based management is to select indicator targets and limit reference points (eg. Borja et al., 2012; Rossberg et al., 2017; Samhouri et al., 2012) that are designed to protect or optimize ecosystem-wide values rather than resource-specific values. Related approaches include habitat protection and other aspects of spatial planning and management and operational models such as fishery-ecosystem models. Habitat is the nexus of all three aspects of ecosystem integrity (Fig. 2), and thus the health of habitat types is a useful and natural way to visualize, assess, and manage ecosystem health generally (e.g. Levin and Stunz, 2005; Peterson et al., 2000). This was inherent in the design of the present approach to indicators development.

The present approach is not explicitly designed for application to circumstances wherein one type of stressor is of heightened interest, such as a catastrophic oil-spill, which would be most effectively assessed with tailored sets of indicators, or emerging stressors such as climate change (but see Table D.1). Such applications are desirable but would ideally require new iterations of expert feedback relating to those stressors rather than simple reorganizations of the indicators that emerged from the present more general exercise about ecosystem integrity. 
Alternatively, a review of indicators of oil spills or climate change may enable an interim adoption of such special indicators into the present framework.

The hierarchical expert-based approach employed here to develop sets of these simple indicators was designed to represent the broadest aspects and values of each ecosystem feature the broader marine ecosystem, thereby at least partially addressing the concern raised by de Jonge et al. (2012) that the use of simple indicators often does not adequately represent the true complexity of coastal and marine social-ecological systems (see also Loomis and Paterson, 2014). The approach appears to achieve this representativeness, but each selected indicator needs testing in practice, e.g. to determine if they perform well against encountered pressure gradients. Moreover, the continued development and application of more holistic or integrative indicator types will be an important complement to the approach of using broad sets of simple indicators. Well known fisheries indicators such as fishing mortality and maximum sustainable yield did not emerge prominently because the focus herein was on populations and communities rather than fishery-dependent indicators of targeted stocks.

The selection of a reasonably small set of indicators that represents the status of the ecosystem and the pressures on it, and a complementary set that represents the status of the connected human dimension and the pressures on it, is a key foundation for operationalizing ecosystem-based assessment and management in the context of Integrated Ecosystem Assessment. The goal for Canada's Pacific marine ecosystems was to develop a flexible and adaptive approach to develop such sets of indicators. The present exercise has informed us that issues of scale and complexity necessitate an adaptive 'tool box' approach involving a range of expert-ranked indicators that can be applied in a flexible way in different contexts.

\section{Conclusions}

The complexity of Canada's Pacific Marine Ecosystems and the dual goals of (1) developing useful and representative indicators of ecosystem state and pressures and (2) promoting assessment and management partnerships with coastal communities led to the development of the present hierarchical, expert-based, and adaptive approach to indicator development. The resulting sets of indicators optimally represent the integrity or health of the ecosystem and the pressures on it from the perspective of regional experts and given that the resulting indicators have yet to be tested in practice. This flexible "toolbox" can be used to select representative sets of indicators for any scales of interest in Canada's Pacific marine ecosystems, or any region in which the approach is developed. Locally-relevant features and values can be emphasized in local applications of these regionally-relevant indicator sets. This can promote assessment and management partnerships among coastal communities including indigenous communities.

With modification, this adaptable and flexible expert-based approach should also enable application to a wide variety of issues including applications to stressors of interest such as catastrophic oil spills and suites of climate change variables. These indicators should be even more useful when complemented with holistic/integrative indicators and existing resource- 
focused indicators, as well as performance-based approaches to ecological indicator development (e.g. Perry and Masson, 2013). Some limits of expert-based approaches were encountered, indicating that simplicity of surveys maximizes participation.

Next steps include the articulation of measurable indicator metrics, target and limit reference points, sampling (monitoring) designs, institutional and human resource capacities and partnerships, and adequate investment. To implement a regional monitoring program that includes nested local monitoring programs, an overarching platform is needed with functions that include georeferenced sampling stations, communication of sampling protocols, data entry and management, networking and collaboration, knowledge mobilization, repository functions, privacy, and complementarity with existing networks and data management systems. The Local Environmental Observer (LEO) Network (leonetwork.org) is one example of such an emerging system.

\section{Acknowledgements}

The work could not have been conducted without the willingness and efforts of the 200+ experts who participated in the 17 expert panels and who otherwise participated in the various steps of this initiative through online surveys and workshops. Government departments such as Fisheries and Oceans Canada, Parks Canada, Environment and Climate Change Canada, and BC Ministry of Environment contributed staff time. The Pew Charitable Trusts enabled me to conceptualize, initiate, and conduct this work through a Pew Fellowship in Marine Conservation. The Gordon and Betty Moore Foundation and the Oak Foundation supported additional development through West Coast Aquatic. The completion of this work was inspired by the OceanCanada Partnership supported by the Social Sciences and Humanities Research Board of Canada, and by a working group entitled Understanding Changes in the Coastal Gulf of Alaska Social-Ecological System supported by the Gulf Watch Alaska program from the Exxon Valdez Oil Spill Trustee Council and convened at the National Center for Ecological Analysis and Synthesis, University of California, Santa Barbara, and by the State of California. No funding sources had any involvement in the design, collection, analysis and interpretation of data, in the writing, or the decision to submit the article for publication. The British Columbia Marine Conservation Analysis shared some contact information for experts. The quality of the manuscript was improved through input by S. King, K. Wallace, S. Klain, A. Day, J. Samouri and $\mathrm{T}$. Takaro, and by three anonymous reviewers.

\section{Appendix A. Supplementary data}

Available on the OSF project page associated with this paper. 


\section{References}

Adams, S.M. 2005. Assessing cause and effect of multiple stressors on marine systems. Mar. Pollut. Bull. 51, 649-657. http://dx.doi.org/10.1016/j.marpolbul.2004.11.040

Ainsworth, C.H., Samhouri, J.F., Busch, D.S., Cheung, W.W.L., Dunne, J., Okey, T.A. 2011. Potential impacts of climate change on Northeast Pacific marine foodwebs and fisheries. ICES J. Mar. Sci. 68, 1217-1229. http://dx.doi.org/10.1093/icesjms/fsr043

Andrews, K.S., Harvey, C.J., Levin., P.S. 2013. Conceptual models and indicator selection process for Washington State's marine spatial planning process. Final report. NWFSC, NOAA. 120 pp. Available online: http://www.msp.wa.gov/wpcontent/uploads/2013/07/NOAA NWFSC ConceptualModel FinalReport.pdf.

Anonymous. 2012. Ocean Health Index Shows Room for Improvement. Science 337, 784-784.

Ban, S.S., Alidina, H., Okey, T.A., Gregg, R., Ban, N. 2016. Identifying potential marine climate change refugia: A case study in Canada's Pacific marine ecosystems. Global Ecology and Conservation, 41-54, DOI: 10.1016/j.gecco.2016.07.004 http://dx.doi.org/10.1016/j.gecco.2016.07.004

Belfiore, S., Barbière, J., Bowen, R., Cicin-Sain, B., Ehler, C., Mageau, C., et al. 2006. A handbook for measuring the progress and outcomes of integrated coastal and ocean management. IOC Manuals and Guides 46, ICAM Dossier, 2. Paris, Intergovernmental Oceanographic Commission, UNESCO. In: Heileman S, editor. 46.

Berkes, F., Berkes, M.K., Fast, H. 2007. Collaborative integrated management in Canada's north: The role of local and traditional knowledge and community-based monitoring. Coast. Manage. 35, 143 162. http://dx.doi.org/10.1080/08920750600970487

Blanfune, A., Thibaut, T., Boudouresque, C.F., Macic, V., Markovic, L., Palomba, L., et al. 2017. The CARLIT method for the assessment of the ecological quality of European Mediterranean waters: Relevance, robustness and possible improvements. Ecological Indicators 72, 249-259. http://dx.doi.org/10.1016/j.ecolind.2016.07.049

Borja, A., Bald, J., Franco, J., Larreta, J., Muxika, I., Revilla, M., et al. 2009a. Using multiple ecosystem components, in assessing ecological status in Spanish (Basque Country) Atlantic marine waters. Mar. Pollut. Bull. 59, 54-64. http://dx.doi.org/10.1016/j.marpolbul.2008.11.010

Borja, A., Dauer, D.M., Gremare, A. 2012. The importance of setting targets and reference conditions in assessing marine ecosystem quality. Ecological Indicators 12, 1-7. http://dx.doi.org/10.1016/j.ecolind.2011.06.018

Borja, A., Elliott, M., Andersen, J.H., Berg, T., Carstensen, J., Halpern, B.S., et al. 2016. Overview of Integrative Assessment of Marine Systems: The Ecosystem Approach in Practice. Frontiers in Marine Science 3. http://dx.doi.org/10.3389/fmars.2016.00020

Borja, A., Elliott, M., Andersen, J.H., Cardoso, A.C., Carstensen, J., Ferreira, J.G., et al. 2013. Good Environmental Status of marine ecosystems: What is it and how do we know when we have attained it? Mar. Pollut. Bull. 76, 16-27. http://dx.doi.org/10.1016/j.marpolbul.2013.08.042

Borja, A., Elliott, M., Carstensen, J., Heiskanen, A.S., van de Bund, W. 2010. Marine management Towards an integrated implementation of the European Marine Strategy Framework and the Water Framework Directives. Mar. Pollut. Bull. 60, 2175-2186. http://dx.doi.org/10.1016/j.marpolbul.2010.09.026

Borja, A., Galparsoro, I., Solaun, O., Muxika, I., Tello, E.M., Uriarte, A., et al. 2006. The European Water Framework Directive and the DPSIR, a methodological approach to assess the risk of 
failing to achieve good ecological status. Estuar. Coast. Shelf Sci. 66, 84-96.

http://dx.doi.org/10.1016/j.ecss.2005.07.021

Borja, A., Prins, T.C., Simboura, N., Andersen, J.H., Berg, T., Marques, J.-C., et al. 2014. Tales from a thousand and one ways to integrate marine ecosystem components when assessing the environmental status. Frontiers in Marine Science 1. http://dx.doi.org/10.3389/fmars.2014.00072

Borja, A., Ranasinghe, A., Weisberg, S.B. 2009b. Assessing ecological integrity in marine waters, using multiple indices and ecosystem components: Challenges for the future. Mar. Pollut. Bull. 59, 1-4. http://dx.doi.org/10.1016/j.marpolbul.2008.11.006

Bourdaud, P., Gascuel, D., Bentorcha, A., Brind'Amour, A. 2016. New trophic indicators and target values for an ecosystem-based management of fisheries. Ecological Indicators 61, 588-601. http://dx.doi.org/10.1016/j.ecolind.2015.10.010

Boutilier, S. 2017. Free, Prior, and Informed Consent and Reconciliation in Canada: Proposals to Implement Articles 19 and 32 of the UN Declaration on the Rights of Indigenous Peoples. West. J. Leg. Stud. 7, 22.

Branch, T.A., Watson, R., Fulton, E.A., Jennings, S., McGilliard, C.R., Pablico, G.T., et al. 2010. The trophic fingerprint of marine fisheries. Nature 468, 431-435.

http://dx.doi.org/10.1038/nature09528

Brubaker, M., Berner, J., Tcheripanoff, M. 2013. LEO, the Local Environmental Observer Network: a community-based system for surveillance of climate, environment, and health events. International Journal of Circumpolar Health 72, 513-514.

Bunnefeld, N., Hoshino, E., Milner-Gulland, E.J. 2011. Management strategy evaluation: a powerful tool for conservation? Trends in Ecology \& Evolution 26, 441-447.

http://dx.doi.org/10.1016/j.tree.2011.05.003

Burgass, M.J., Halpern, B.S., Nicholson, E., Milner-Gulland, E.J. 2017. Navigating uncertainty in environmental composite indicators. Ecological Indicators 75, 268-278. http://dx.doi.org/10.1016/j.ecolind.2016.12.034

Chandler, P.C., King, S.A., Boldt, J. 2017. State of the physical, biological and selected fishery resources of Pacific Canadian marine ecosystems in 2016. Can. Tech. Rep. Fish. Aquat. Sci. 3225: $243+$ vi p.

Cheung, W.L., Brodeur, R.D., Okey, T.A., Pauly, D. 2015. Projecting future changes in distributions of pelagic fish species of Northeast Pacific shelf seas. Prog. Oceanogr. 130, 19-31.

Cisneros-Montemayor, A.M., Cheung, W.W.L., Bodtker, K., Teh, L., Steiner, N., Bailey, M., et al. 2017. Towards an integrated database on Canadian ocean resources: benefits, current states, and research gaps. Can. J. Fish. Aquat. Sci. 74, 65-74. http://dx.doi.org/10.1139/cjfas-2015-0573

Coll, M., Shannon, L.J., Kleisner, K.M., Juan-Jorda, M.J., Bundy, A., Akoglu, A.G., et al. 2016. Ecological indicators to capture the effects of fishing on biodiversity and conservation status of marine ecosystems. Ecological Indicators 60, 947-962. http://dx.doi.org/10.1016/j.ecolind.2015.08.048

Coll, M., Shannon, L.J., Yemane, D., Link, J.S., Ojaveer, H., Neira, S., et al. 2010. Ranking the ecological relative status of exploited marine ecosystems. ICES J. Mar. Sci. 67, 769-786. http://dx.doi.org/10.1093/icesjms/fsp261

Costanza, R., Norton, B.G., Haskell, B.D. 1992. Ecosystem health: new goals for environmental management: Island Press. 
Crochemore, L., Perrin, C., Andreassian, V., Ehret, U., Seibert, S.P., Grimaldi, S., et al. 2015. Comparing expert judgement and numerical criteria for hydrograph evaluation. Hydrol. Sci. J.-J. Sci. Hydrol. 60, 402-423. http://dx.doi.org/10.1080/02626667.2014.903331

Cummins, P., Haigh, R. 2010. Ecosystem Status and Trends Report for North Coast and Hecate Strait ecozone, British Columbia. DFO Can. Sci. Advis. Sec. Res. Doc. 2010/045. iv + 61 p.

Cury, P.A., Christensen, V. 2005. Quantitative ecosystem indicators for fisheries management Introduction. ICES J. Mar. Sci. 62, 307-310. http://dx.doi.org/10.1016/j.icesjms.2005.02.003

Daigle, R.M., Archambault, P., Halpern, B.S., Lowndes, J.S.S., Cote, I.M. 2017. Incorporating public priorities in the Ocean Health Index: Canada as a case study. Plos One 12. http://dx.doi.org/10.1371/journal.pone.0178044

Dale, V.H., Beyeler, S.C. 2001. Challenges in the development and use of ecological indicators. Ecological Indicators 1, 3-10.

de Jonge, V.N., Pinto, R., Turner, R.K. 2012. Integrating ecological, economic and social aspects to generate useful management information under the EU Directives' 'ecosystem approach'. Ocean Coastal Manage. 68, 169-188. http://dx.doi.org/10.1016/j.ocecoaman.2012.05.017

DFO. 2000. State of the Pacific Ocean 1999. DFO Sci. Ocean Status Report. 2000/001, pp. 38.

DFO. 2007. Eastern Scotian Shelf Integrated Ocean Management Plan: Strategic Plan. Oceans and Habitat Branch, Fisheries and Oceans Canada, Dartmouth, Nova Scotia, 68 pp., pp. 68.

DFO. 2009. Development of a framework and principles for the biogeographic classification of Canadian marine areas. DFO Can. Sci. Adv. Sec. Sci. Adv. Rep. 2009/056.

DFO. 2010. 2010 Canadian Marine Ecosystem Status and Trends Report. DFO Can. Sci. Advis. Sec. Sci. Advis. Rep. 2010/030 (Revised).

DFO. 2012. Canada's State of the Oceans Report, 2012. Fisheries and Oceans Canada, DFO/2012-1818., pp. 38.

Doak, D.F., Estes, J.A., Halpern, B.S., Jacob, U., Lindberg, D.R., Lovvorn, J., et al. 2008. Understanding and predicting ecological dynamics: Are major surprises inevitable? Ecology 89, 952-961.

Doren, R.F., Trexler, J.C., Gottlieb, A.D., Harwell, M.C. 2009. Ecological indicators for system-wide assessment of the greater everglades ecosystem restoration program. Ecological Indicators 9, S2S16. http://dx.doi.org/10.1016/j.ecolind.2008.08.009

Elliott, M. 2002. The role of the DPSIR approach and conceptual models in marine environmental management: an example for offshore wind power. Mar. Pollut. Bull. 44, III-VII.

Foley, M.M., Halpern, B.S., Micheli, F., Armsby, M.H., Caldwell, M.R., Crain, C.M., et al. 2010. Guiding ecological principles for marine spatial planning. Marine Policy 34, 955-966. http://dx.doi.org/10.1016/j.marpol.2010.02.001

Frazier, M., Longo, C., Halpern, B.S. 2016. Mapping Uncertainty Due to Missing Data in the Global Ocean Health Index. Plos One 11. http://dx.doi.org/10.1371/journal.pone.0160377

Fulton, E.A., Smith, A.D.M., Punt, A.E. 2005. Which ecological indicators can robustly detect effects of fishing? ICES J. Mar. Sci. 62, 540-551.

Fulton, E.A., Smith, A.D.M., Smith, D.C., Johnson, P. 2014. An Integrated Approach Is Needed for Ecosystem Based Fisheries Management: Insights from Ecosystem-Level Management Strategy Evaluation. Plos One 9, 16. http://dx.doi.org/10.1371/journal.pone.0084242

Gan, X.Y., Fernandez, I.C., Guo, J., Wilson, M., Zhao, Y.Y., Zhou, B.B., et al. 2017. When to use what: Methods for weighting and aggregating sustainability indicators. Ecological Indicators 81, 491502. http://dx.doi.org/10.1016/j.ecolind.2017.05.068 
Halpern, B.S., Longo, C., Hardy, D., McLeod, K.L., Samhouri, J.F., Katona, S.K., et al. 2012. An index to assess the health and benefits of the global ocean. Nature 488, 615-+. http://dx.doi.org/10.1038/nature11397

Harwell, M.A., Myers, V., Young, T., Bartuska, A., Gassman, N., Gentile, J.H., et al. 1999. A framework for an ecosystem integrity report card. Bioscience 49, 543-556. http://dx.doi.org/10.2307/1313475

Heesemann, M., Insua, T.L., Scherwath, M., Juniper, S.K., Moran, K. 2014. Ocean Networks Canada: From geohazards research laboratories to smart ocean systems. Oceanography 27, 151-153.

Heiskanen, A.-S., Berg, T., Uusitalo, L., Teixeira, H., Bruhn, A., Krause-Jensen, D., et al. 2016. Biodiversity in Marine Ecosystems-European Developments toward Robust Assessments. Frontiers in Marine Science 3. http://dx.doi.org/10.3389/fmars.2016.00184

Hobday, A.J., Okey, T.A., Poloczanska, E.S., Kunz, T.J., Richardson, A.J. 2006. Impacts of climate change on Australian marine life. A report prepared by CSIRO Marine and Atmospheric Research for the Department of the Environment and Heritage, Australian Greenhouse Office, Canberra, Australia.

Hummel, H., Frost, M., Juanes, J.A., Kochmann, J., Bolde, C., Aneiros, F., et al. 2015. A comparison of the degree of implementation of marine biodiversity indicators by European countries in relation to the Marine Strategy Framework Directive (MSFD). Journal of the Marine Biological Association of the United Kingdom 95, 1519-1531. http://dx.doi.org/10.1017/s0025315415000235

Hunt, B.P.V., Jackson, J.M., Wang, K., Beluz, J.d.b. 2017. Hakai oceanography program: British Columbia Central Coast time series (2012-2016), p. 145-150. In Chandler, P.C., King, S.A., and Boldt, J. (Eds.). State of the physical, biological and selected fishery resources of Pacific Canadian marine ecosystems in 2016. Can. Tech. Rep. Fish. Aquat. Sci. 3225: 243 + vi p.

Hupp, J., Brubaker, M., Wilkinson, K., Williamson, J. 2015. How are your berries? Perspectives of Alaska's environmental managers on trends in wild berry abundance. International journal of circumpolar health 74, 28704-28704. http://dx.doi.org/10.3402/ijch.v74.28704

Hyman, J.B., Leibowitz, S.G. 2001. JSEM: A framework for identifying and evaluating indicators. Environmental Monitoring and Assessment 66, 207-232. http://dx.doi.org/10.1023/a:1006397031160

Ianson, D., Flostrand, L. 2010. Ecosystem Status and Trends Report: Coastal waters off the west coast of Vancouver Island, British Columbia. iv. FIsheries and Oceans Canada, DFO Can. Sci. Advis. Sec. , pp. 58 p.

James, C.A., Kershner, J., Samhouri, J., O'Neill, S., Levin, P.S. 2012. A methodology for evaluating and ranking water quantity indicators in support of ecosystem-based management. Environmental Management 49, 703-719. http://dx.doi.org/10.1007/s00267-012-9808-7

Jennings, S. 2005. Indicators to support an ecosystem approach to fisheries. Fish Fish. 6, 212-232. http://dx.doi.org/10.1111/j.1467-2979.2005.00189.x

Johannessen, S.C., McCarter, B. 2010. Ecosystem Status and Trends Report for the Strait of Georgia ecozone. DFO Can. Sci. Advis. Sec. Res. Doc. 2010/010. vi +45.

Jørgensen, S.E., Xu, F.-L., Costanza, R. 2010. Handbook of ecological indicators for assessment of ecosystem health. Boca Raton, FL: CRC Press/Taylor \& Francis. 
Kershner, J., Samhouri, J.F., James, C.A., Levin, P.S. 2011. Selecting indicator portfolios for marine species and food webs: A Puget Sound case study. PLoS ONE 6, e25248. http://dx.doi.org/10.1371/journal.pone.0025248

Klain, S.C., Beveridge, R., Bennett, N.J. 2014. Ecologically sustainable but unjust? Negotiating equity and authority in common-pool marine resource management. Ecology and Society 19, 52.

Langhans, S.D., Reichert, P., Schuwirth, N. 2014. The method matters: A guide for indicator aggregation in ecological assessments. Ecological Indicators 45, 494-507. http://dx.doi.org/10.1016/j.ecolind.2014.05.014

Levin, P., Fogarty, M., Matlock, G., Ernst, M. 2008. Integrated Ecosystem Assessments. U.S. Dept. Commer., NOAA Tech. Memo. NMFS-NWFSC-92, 20 p.

Levin, P.S., A., J., Kershner, J., O’Neill, S., Francis, T., Samhouri, J., et al. 2011. The Puget Sound ecosystem: what is our desired future and how do we measure progress along the way? Puget Sound Science Update. pugetsoundscienceupdate.com accessed on 19 January 2011. Puget Sound Partnership. Tacoma, Washington.

Levin, P.S., Fogarty, M.J., Murawski, S.A., Fluharty, D. 2009. Integrated Ecosystem Assessments: Developing the Scientific Basis for Ecosystem-Based Management of the Ocean. Plos Biology 7 , 23-28. http://dx.doi.org/10.1371/journal.pbio.1000014

Levin, P.S., Stunz, G.W. 2005. Habitat triage for exploited fishes: Can we identify essential "Essential Fish Habitat?". Estuar. Coast. Shelf Sci. 64, 70-78. http://dx.doi.org/10.1016/j.ecss.2005.02.007

LGC. 2014. Socio-Economic, Cultural and Ecological Assessment of the Central Coast Marine Plan. Prepared for the Marine Planning Partnership of the North Coast by Lions Gate Consulting Inc., Robinson Consulting Associates Ltd., Peak Solutions Consulting Inc., and Coastal and Ocean Resources, pp. 102.

Link, J.S., Browman, H.I. 2014. Integrating what? Levels of marine ecosystem-based assessment and management Introduction. ICES J. Mar. Sci. 71, 1170-1173. http://dx.doi.org/10.1093/icesjms/fsu026

Liu, J.G., Dietz, T., Carpenter, S.R., Alberti, M., Folke, C., Moran, E., et al. 2007. Complexity of coupled human and natural systems. Science 317, 1513-1516. http://dx.doi.org/10.1126/science.1144004

Loomis, D.K., Paterson, S.K. 2014. Human dimensions indicators of coastal ecosystem services: A hierarchical perspective. Ecological Indicators 44, 63-68. http://dx.doi.org/10.1016/j.ecolind.2013.12.022

Lucas, B.G., Verrin, S., Brown, R. 2007. Ecosystem overview: Pacific North Coast Integrated Management Area (PNCIMA). Can. Tech. Rep. Fish. Aquat. Sci. 2667: xiii + 104 p.

Marliave, J., Challenger, W. 2009. Monitoring and evaluating rockfish conservation areas in British Columbia. Can. J. Fish. Aquat. Sci. 66, 995-1006. http://dx.doi.org/10.1139/f09-056

Masi, M.D., Ainsworth, C.H., Jones, D.L. 2017. Using a Gulf of Mexico Atlantis model to evaluate ecological indicators for sensitivity to fishing mortality and robustness to observation error. Ecological Indicators 74, 516-525. http://dx.doi.org/10.1016/j.ecolind.2016,11.008

Masson, D., Perry, R.I. 2013. The Strait of Georgia Ecosystem Research Initiative: An overview. Prog. Oceanogr. 115, 1-5. http://dx.doi.org/10.1016/j.pocean.2013.05.009

Methratta, E.T., Link, J.S. 2006. Evaluation of quantitative indicators for marine fish communities. Ecological Indicators 6, 575-588. http://dx.doi.org/10.1016/j.ecolind.2005.08.022

MPPI. 2016. Regional Action Framework. Marine Plan Partnership Initiative, British Columbia, pp. 37. 
MSRA. 2002. British Columbia marine ecological classification: marine ecosections and ecounits, Version 2. Resources Information Standards Committee, British Columbia Ministry of Sustainable Resource Management. Resources Information Standards Committee, British Columbia Ministry of Sustainable Resource Management, pp. 49.

Myers, R.A., Worm, B. 2003. Rapid worldwide depletion of predatory fish communities. Nature 423, 280-283. http://dx.doi.org/10.1038/nature01610

Niemeijer, D., de Groot, R.S. 2008. A conceptual framework for selecting environmental indicator sets. Ecological Indicators 8, 14-25. http://dx.doi.org/10.1016/j.ecolind.2006.11.012

Niemi, G.J., McDonald, M.E. 2004. Application of ecological indicators. Annual Review of Ecology Evolution and Systematics 35, 89-111. http://dx.doi.org/10.1146/annurev.ecolsys.35.112202.130132

O'Neill, S.M., Bravo, C.F., Collier, T.K. 2008. Environmental Indicators for the Puget Sound Partnership: A Regional Effort to Select Provisional Indicators (Phase 1). Summary Report. 2008. National Oceanic and Atmospheric Administration: Seattle, WA.

Okey, T.A., Alidina, H.M., Agbayani, S. 2015. Mapping ecological vulnerability to recent climate change in Canada's Pacific marine ecosystems. Ocean Coastal Manage. 106, 35-48. http://dx.doi.org/http://dx.doi.org/10.1016/j.ocecoaman.2015.01.009

Okey, T.A., Alidina, H.M., Lo, V., Jessen, S. 2014. Effects of climate change on Canada's Pacific marine ecosystems: a summary of scientific knowledge. Rev. Fish. Biol. Fish. 24, 519-559. http://dx.doi.org/10.1007/s11160-014-9342-1

Okey, T.A., Loucks, L.A. 2011. Social-ecological assessment for the marine and coastal areas of the West Coast of Vancouver Island. The Tsawalk Partnership, West Coast Aquatic, Port Alberni, BC, Canada.

Okey, T.A., Wallace, K.L., Klain, S. 2011. Developing marine ecological indicators for integrated ecosystem-based planning and management in coastal British Columbia. In: Okey TA, Loucks LA, editors. Social-ecological assessment of the marine and coastal areas of the West Coast of Vancouver Island. The Tsawalk Partnership, West Coast Aquatic, Port Alberni, BC.

Oppenheimer, M., Little, C.M., Cooke, R.M. 2016. Expert judgement and uncertainty quantification for climate change. Nature Climate Change 6, 445-451. http://dx.doi.org/10.1038/nclimate2959

Pauly, D., Christensen, V., Dalsgaard, J., Froese, R., Torres, F. 1998. Fishing down marine food webs. Science 279, 860-863. http://dx.doi.org/10.1126/science.279.5352.860

Perry, R.I., Masson, D. 2013. An integrated analysis of the marine social-ecological system of the Strait of Georgia, Canada, over the past four decades, and development of a regime shift index. Prog. Oceanogr. 115, 14-27. http://dx.doi.org/10.1016/j.pocean.2013.05.021

Peterson, C.H., Summerson, H.C., Thomson, E., Lenihan, H.S., Grabowski, J., Manning, L., et al. 2000. Synthesis of linkages between benthic and fish communities as a key to protecting essential fish habitat. Bulletin of Marine Science 66, 759-774.

Pinto, R., de Jonge, V.N., Marques, J.C. 2014. Linking biodiversity indicators, ecosystem functioning, provision of services and human well-being in estuarine systems: Application of a conceptual framework. Ecological Indicators 36, 644-655. http://dx.doi.org/10.1016/j.ecolind.2013.09.015

Poloczanska, E.S., Babcock, R.C., Butler, A., Hobday, A., Hoegh-Guldberg, O., Kunz, T.J., et al. 2007. Climate change and Australian marine life. Oceanography and Marine Biology 45, 407-478.

Poloczanska, E.S., Hobday, A.J., Richardson, A.J. 2012. Marine Cliimate Change in Australia, Impacts and Adaptation Responses. 2012 Report Card. ISBN 978-0-643-10927-8. 
Probst, W.N., Lynam, C.P. 2016. Integrated assessment results depend on aggregation method and framework structure - A case study within the European Marine Strategy Framework Directive. Ecological Indicators 61, 871-881. http://dx.doi.org/10.1016/j.ecolind.2015.10.040

Queirós, A.M., Strong, J.A., Mazik, K., Carstensen, J., Bruun, J., Somerfield, P.J., et al. 2016. An Objective Framework to Test the Quality of Candidate Indicators of Good Environmental Status. Frontiers in Marine Science 3. http://dx.doi.org/10.3389/fmars.2016.00073

Raygorodetsky, G., Chetkiewicz, C. 2017. Watching, Listening and Learning to Understand Change: Developing a Community-Based Monitoring (CBM) Initiative in Ontario's Far North. Wildlife Conservation Society Canada, Toronto, Ontario, Canada.

RCA. 2012. Socio-economic and Cultural Overview and Assessment Report for the Pacific North Coast Integrated Management Area. Prepared by Robinson Consulting and Associates Ltd. for Fisheries and Oceans Canada, Victoria, BC.

Rice, J.C., Rochet, M.J. 2005. A framework for selecting a suite of indicators for fisheries management. ICES J. Mar. Sci. 62, 516-527. http://dx.doi.org/10.1016/j.icesjms.2005.01.003

Rochet, M.J., Rice, J.C. 2005. Do explicit criteria help in selecting indicators for ecosystem-based fisheries management? ICES J. Mar. Sci. 62, 528-539. http://dx.doi.org/10.1016/j.icesjms.2005.01.007

Rossberg, A.G., Uusitalo, L., Berg, T., Zaiko, A., Chenuil, A., Uyarra, M.C., et al. 2017. Quantitative criteria for choosing targets and indicators for sustainable use of ecosystems. Ecological Indicators 72, 215-224. http://dx.doi.org/10.1016/j.ecolind.2016.08.005

Samhouri, J.F., Lester, S.E., Selig, E.R., Halpern, B.S., Fogarty, M.J., Longo, C., et al. 2012. Sea sick? Setting targets to assess ocean health and ecosystem services. Ecosphere 3. http://dx.doi.org/10.1890/es11-00366.1

Samhouri, J.F., Levin, P.S., James, C.A., Kershner, J., Williams, G. 2011. Using existing scientific capacity to set targets for ecosystem-based management: A Puget Sound case study. Marine Policy 35, 508-518. http://dx.doi.org/10.1016/j.marpol.2010.12.002

Shannon, L., Coll, M., Bundy, A., Gascuel, D., Heymans, J.J., Kleisner, K., et al. 2014. Trophic levelbased indicators to track fishing impacts across marine ecosystems. Mar. Ecol. Prog. Ser. 512, 115-140. http://dx.doi.org/10.3354/meps10821

Shin, Y.J., Bundy, A., Shannon, L.J., Blanchard, J.L., Chuenpagdee, R., Coll, M., et al. 2012. Global in scope and regionally rich: an IndiSeas workshop helps shape the future of marine ecosystem indicators. Rev. Fish. Biol. Fish. 22, 835-845. http://dx.doi.org/10.1007/s11160-012-9252-z

Smith, A.D.M., Sainsbury, K.J., Stevens, R.A. 1999. Implementing effective fisheries-management systems: Management strategy evaluation and the Australian partnership approach. ICES J. Mar. Sci. 56, 967-979.

Suffling, R., Scott, D. 2002. Assessment of climate change effects on Canada's National Park system. Environmental Monitoring and Assessment 74, 117-139.

http://dx.doi.org/10.1023/a:1013810910748

Tallis, H., Levin, P.S., Ruckelshaus, M., Lester, S.E., McLeod, K.L., Fluharty, D.L., et al. 2010. The many faces of ecosystem-based management: Making the process work today in real places. Marine Policy 34, 340-348. http://dx.doi.org/10.1016/j.marpol.2009.08.003

Teixeira, H., Berg, T., Uusitalo, L., Fürhaupter, K., Heiskanen, A.-S., Mazik, K., et al. 2016. A Catalogue of Marine Biodiversity Indicators. Frontiers in Marine Science 3. http://dx.doi.org/10.3389/fmars.2016.00207 
Tett, P., Gowen, R.J., Painting, S.J., Elliott, M., Forster, R., Mills, D.K., et al. 2013. Framework for understanding marine ecosystem health. Mar. Ecol. Prog. Ser. 494, 1-27. http://dx.doi.org/10.3354/meps10539

Turner, K.L., Bitonti, C.P. 2011. Conservancies in British Columbia, Canada: Bringing Together Protected Areas and First Nations' Interests. International Indigenous Policy Journal 2.

Uusitalo, L., Blanchet, H., Andersen, J.H., Beauchard, O., Berg, T., Bianchelli, S., et al. 2016. IndicatorBased Assessment of Marine Biological Diversity-Lessons from 10 Case Studies across the European Seas. Frontiers in Marine Science 3. http://dx.doi.org/10.3389/fmars.2016.00159

Walsh, J.E., Thoman, R.L., Bhatt, U.S., Bieniek, P.A., Brettschneider, B., Brubaker, M., et al. 2017. The high latitude marine heat wave of 2016 and its impacts on Alaska [in "Explaining Extreme Events of 2016 from a Climate Perspective"]. Bulletin of the American Meteorological Society 98, S39S43. http://dx.doi.org/10.1175/BAMS-D-17-0105.1

Walters, C.J. 1986. Adaptive management of renewable resources. New York: Macmillan Publishing Co. WCA. 2012. Coastal Strategy for the West Coast Vancouver Island. West Coast Aquatic, Port Alberni. pp. 43.

Wilson, N.J., Mutter, E., Inkster, J., Satterfield, T. 2018. Community-Based Monitoring as the practice of Indigenous governance: A case study of Indigenous-led water quality monitoring in the Yukon River Basin. Journal of Environmental Management 210, 290-298. http://dx.doi.org/10.1016/j.jenvman.2018.01.020

Wong, C., Rylko, M. 2014. Health of the Salish Sea as measured using transboundary ecosystem indicators. Aquat. Ecosyst. Health Manage. 17, 463-471. http://dx.doi.org/10.1080/14634988.2014.980209

Woodley, E., Crowley, E., de Pryck, J.D., Carmen, A. 2009. Cultural indicators of Indigenous Peoples' food and agro-ecological systems. Report prepared by the SARD Institute for the FAO and the International Indian Treaty Council (IITC) pp. 19.

WSASC. 2012. Sound Indicators: A Review for the Puget Sound Partnership. Washington State Academy of Sciences Committee.

Zador, S.G., Holsman, K.K., Aydin, K.Y., Gaichas, S.K. 2017. Ecosystem considerations in Alaska: the value of qualitative assessments. ICES J. Mar. Sci. 74, 421-430.

http://dx.doi.org/10.1093/icesjms/fsw144 